\title{
Presentation intervals and the impact of delay on breast cancer progression in a black African population
}

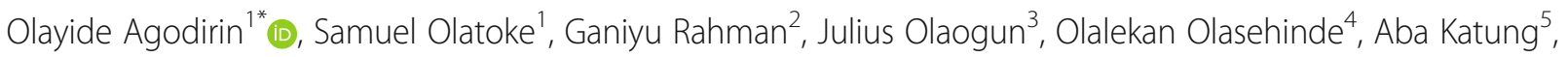
Oladapo Kolawole ${ }^{6}$, Omobolaji Ayandipo ${ }^{7}$, Amarachukwu Etonyeaku', Olufemi Habeeb ${ }^{1}$, Ademola Adeyeye ${ }^{9}$, John Agboola ${ }^{10}$, Halimat Akande ${ }^{11}$, Soliu Oguntola ${ }^{12}$, Olusola Akanbi ${ }^{12}$ and Oluwafemi Fatudimu ${ }^{13}$

\begin{abstract}
Background: The help-seeking interval and primary-care interval are points of delays in breast cancer presentation. To inform future intervention targeting early diagnosis of breast cancer, we described the contribution of each interval to the delay and the impact of delay on tumor progression.

Method: We conducted a multicentered survey from June 2017 to May 2018 hypothesizing that most patients visited the first healthcare provider within 60 days of tumor detection. Inferential statistics were by t-test, chi-square test, and Wilcoxon-Signed Rank test at $p$-value 0.05 or $95 \%$ confidence limits. Time-to-event was by survival method. Multivariate analysis was by logistic regression.

Results: Respondents were females between 24 and 95 years $(n=420)$. Most respondents visited FHP within 60 days of detecting symptoms (230 (60, 95\% Cl 53-63). Most had long primary-care (237 of 377 (64 95\% Cl 59-68) and detectionto-specialist (293 (73\% (95\% Cl 68-77)) intervals. The primary care interval (median 106 days, IQR 13-337) was longer than the help-seeking interval (median 42 days, IQR 7-150) Wilcoxon signed-rank test $p=0.001$. There was a strong correlation between the length of primary care interval and the detection-to-specialist interval $(r=0.9,95 \% \mathrm{Cl} 0.88-$ 0.92). Patronizing the hospital, receiving the correct advice, and having a big tumor $(>5 \mathrm{~cm})$ were associated with short intervals.

Tumors were detected early, but most became advanced before arriving at the specialist clinic. The difference in tumor size between detection and arriving at a specialist clinic was $5.0 \pm 4.9 \mathrm{~cm}(95 \% \mathrm{Cl} 4.0-5.0)$. The hazard of progressing from early to locally advanced disease was least in the first 30 days (3\%). The hazard was 31\% in 90 days.

Conclusion: Most respondents presented early to the first healthcare provider, but most arrived late at a specialist clinic. The primary care interval was longer than the help-seeking interval. Most tumors were early at detection but locally advanced before arriving in a specialist clinic. Interventions aiming to shorten the primary care interval will have the most impact on time to breast cancer presentation for specialist oncology care in Nigeria.
\end{abstract}

Keywords: Breast cancer, Help-seeking, Primary-care, Intervals, Tumor progression

\footnotetext{
* Correspondence: cancer1992@yahoo.com

'Department of Surgery, University of llorin and University of Ilorin Teaching Hospital, Ilorin, Kwara state, Nigeria

Full list of author information is available at the end of the article
}

\section{$\triangle B M C$}

C C The Author(s). 2020 Open Access This article is licensed under a Creative Commons Attribution 4.0 International License, which permits use, sharing, adaptation, distribution and reproduction in any medium or format, as long as you give appropriate credit to the original author(s) and the source, provide a link to the Creative Commons licence, and indicate if changes were made. The images or other third party material in this article are included in the article's Creative Commons licence, unless indicated otherwise in a credit line to the material. If material is not included in the article's Creative Commons licence and your intended use is not permitted by statutory regulation or exceeds the permitted use, you will need to obtain permission directly from the copyright holder. To view a copy of this licence, visit http://creativecommons.org/licenses/by/4.0/ The Creative Commons Public Domain Dedication waiver (http://creativecommons.org/publicdomain/zero/1.0/) applies to the data made available in this article, unless otherwise stated in a credit line to the data. 


\section{Background}

Breast cancer (BC) patients in low and middle-income countries (LMICs) and black patients in developed countries harbor symptoms for up to 8-12 months [1-5] before diagnosis and treatment thereby increasing the risk of poor outcome and limiting treatment efficacy [6-9].

Historically, two delay components are recognized in cancer treatment: the patients' delay and the systems' delay $[10,11]$. A recent definition proposes replacing the word delay with the word interval [12]. As illustrated in Olsen et al., the Aarhus statement [13] recognized three subintervals between symptom detection and cancer treatment: (1) The patient-interval (comprising symptom appraisal and help-seeking intervals (HSI) as in Dobson et al. [12]) (2). the doctor interval, and (3) the system interval [13]. The subinterval classification aids the understanding of the continuum by giving more details about the subcomponents [12]. Shortening the interval to treatment is pivotal in controlling BC outcome [10], yet in LMICs where the mortality of the disease is disproportionately high, only a few studies address the intervals or journey of BC patients to treatment [14-16].

Factors linked to delayed presentation of breast cancer are often modifiable-changing with intervention. While much of the focus has been on the events in the patientinterval as causes of delayed presentation, recent reports in Nigeria [17], Ghana [18], and Rwanda [3] show an increasing contribution of events in the provider interval. An understanding of factors influencing the length of each interval is critical to effective interventions; therefore, this research aimed to describe the journey of $\mathrm{BC}$ patients from symptom detection to the specialist clinic in a black African population. The primary objective was to describe the contribution of each interval to the continuum. The secondary objectives were (1) to describe the association between the interval length and the socio-demographics, the disease-related experience(s), and system-related experience(s) (2) To describe the impact of long intervals on $\mathrm{BC}$ progression.

\section{Method}

This research was a questionnaire-based survey in 6 tertiary hospitals in Northcentral and Southwestern Nigeria. The hospitals received referrals from lower cadre public hospitals, private hospitals, or walk-in (self-referral). Recruitment of respondents was between June 2017 and May 2018 after obtaining ethical approval from all participating institutions. Consecutive newly diagnosed $\mathrm{BC}$ patients who consented to participate in the study were recruited until the predetermined sample size. At the time of the survey, $\mathrm{BC}$ patients in Nigeria patronized private and public healthcare services including traditionalists, native healers, faith-based homes, and orthodox medical healthcare providers (community health extension workers (CHEW), nurses, chemists, pharmacists, and doctors).

Based on piloting on 30 respondents where $80 \%$ visited the first healthcare provider (FHP) within 30 days of symptom detection, we hypothesized that most patients would visit their FHP within 60 days. Our sample size was 384, calculating for a descriptive cross-sectional study at a relative precision of $5 \%$ and a confidence level of $95 \%$ (1.96). We increased the sample size to 423 in anticipation of a $10 \%$ nonresponse rate.

\section{Data collection}

Based on insight from the Aarhus statement [13], and review of the methods implemented by Varella-Centelles et al. [19] and Moodley et al. [16], a semi-structured questionnaire was designed and the plan of data collection was mapped. The questionnaire was pilot tested before trained personnel administered it in face-to-face interviews. The questionnaire requested information on socio-demographics, recall of first breast bodily change and events surrounding it, disclosure, and help-seeking patterns (see Additional file 1). The questionnaire was administered to respondents within four weeks of arriving in the specialist clinic (SC) to minimize recall bias. Additionally, respondents were helped to cast their minds back on significant personal, social, religious, regional, or national events surrounding the recalled dates or elapsed periods. Attempts to check for reliability of response or to reconcile discrepancies was by triangulation when possible. [Such as BC awareness, path-way to treatment, personnel(s) visited, tumor size and interval lengths]. Questions likely to influence subsequent response questions were delayed. For instance, religious affiliations were delayed until after responding to the use of alternative medicine. The interview was after the day's medical consultation in the patient's mother tongue or English as preferred by the respondent, noting the use of a translator. Recurrent lesions, language barriers, mental incapacitation, and male sex were exclusion criteria.

Clinical tumor size (T-size) estimated by the patient was used as the surrogate for disease stage using the T1-3 as in the 7th edition of the American Joint Committee on Cancer (AJCC) staging for BC, where T1 was $\leq 2 \mathrm{~cm}$, T2 was $2.1-5 \mathrm{~cm}$, and T3 was $>5 \mathrm{~cm}$. Using the practical routine process of extracting clinical history that relies on the patients' retrospective recall, respondents were asked to estimate their tumor size (self-report) at the following three points: first detection, first contact with FHP, and at first SC attendance. A ruler was used to quantify the estimated tumor size in centimeters, as demonstrated by the patient using their phalanx, finger(s), or clenched fist(s). The T-size estimated at the SC was taken as the current tumor size. The patients' estimate was considered unreliable and excluded 
from analysis if the current size estimated differed by more than $2 \mathrm{~cm}$ from the $\mathrm{T}$-size measured physically and recorded by the clinician in the SC.

In defining interval lengths, we used logical arithmetic derivatives of interval lengths in previous works and recommendations $[4,12,13]$ wherein total delay was $>90$ days, and provider delay was $>30$ days. However, to be pragmatic, we considered our health-system and our patients' behavior to operationalize the interval lengths. Therefore we operationalized the interval lengths as follows:

Appraisal interval (API) - the period from the detection of first breast symptom to first disclosure. Long was $>30$ days) (the API was essential to estimate how long the patients keep the lesion secret).

Help-seeking interval (HSI)-the period from symptom detection to FHP. Long was $>60$ days)(HSI was essential to estimate how long the patient stayed before seeking help).

Primary-care interval (PCI) - the period from the FHP to a specialist clinic. Long was $>30$ days) (PCI was essential to estimate interval length attributable to provider system). And symptom detection-to-specialist clinic interval(SCI) - the period from detection of the first symptom to arriving in a specialist clinic. Long was $>90$ days. (SCI was essential because, in Nigeria, the majority of patients receive tumor-specific therapy in specialist clinics, and long SCI is rife) (Fig. 1). We recorded the intervals in days, weeks, or months, multiplying recording made in weeks by 7 to convert to days, and those made in months by 30 to convert to days.

\section{Statistical analysis}

We compared variables using the chi-square test, paired t-test, Wilcoxon Signed-Rank test, and logistic regression for odds of events as appropriate. We used the correlation coefficient for the relationship between continuous variables. We conducted the time-to-event analysis using the survival method on the assumption that tumor progression depended on elapsed time alone. The analysis of progression was limited to 365 days in 30-day time segments because most patients in Africa present within 8-12 months. A statistically significant $p$-value (two-sided) was $5 \%$.
We presented the number of respondents traversing each interval and compared their relative probabilities because we expect that future interventions will focus on increasing the probability of favorable events such as short intervals. We presented a wide range of result patterns because of the dearth of information despite the importance of $\mathrm{BC}$ in Africa also because there is a lack of consensus on whether to analyze as parametric or nonparametric variables [12]. Additionally, we expected that these figures might serve different purposes in future researches.

\section{Results}

\section{Demographics and premorbid preferences}

There were 423 respondents; we excluded three males leaving 420 females. The majority were the Yoruba tribe, only one required interpreter. The modal age decade was the fifth (Table 1). Most respondents (323 of 358(90, 95\%CI 87-93) [62 unspecified] preferred orthodox medical care before noticing their symptoms, but most did not utilize BC screening. Only 6.0\%(95\% CI 4.0-9.0\%) performed self-breast examination monthly (Table $1 \mathrm{~b})$ hence most lumps were detected inadvertently.

\section{Comparative length of intervals}

The PCI (median 106, 13-337) was significantly longer than the HSI (median 42, 7-150), Wilcoxon-Signed Rank test $p=0.0001$. (paired t-test mean difference $140 \pm$ 442 days (95\% CI 95-186). Most respondents disclosed early within 30 days (330 (81, 95\% CI 77-85) and consulted FHP within 60 days (230 (60, 95\% CI 53-63). Most respondents had long PCI of $>30$ days.(1-7 days in 91(25\% (95\% CI 20-29), 1-30 days in 134 (36 95\% CI $31-41)$ and $>30$ days in 237 out of $377(6495 \%$ CI 59 $68)$. The SCI was > 90 days in 293 of 401 (73\% (95\% CI 68-77), 91-180 days in 70 of 401 (17\% (95\% CI 14-22) and $>180$ days in 226 of 401 (56\% (95\% CI 51-61) (Table 2).

\section{Pattern of disclosure and factors influencing API}

Most respondents informed the first person (primary person) early, and the husband was the most common primary person. The primary person offered the correct advice often (Table 3b), and 276 of 399 (69.2\%) acted in

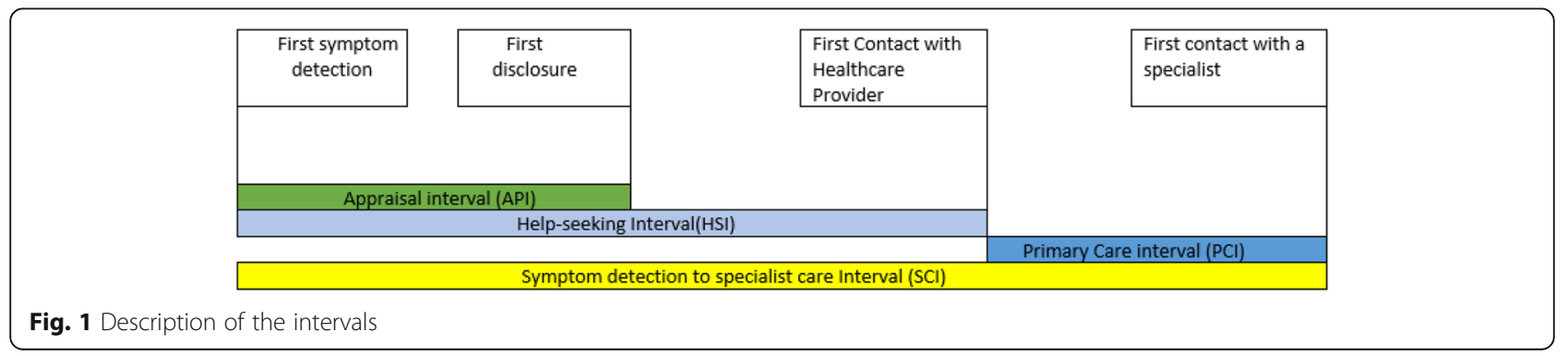


Table 1 The Demographic characteristics of respondents showing age distribution, educational status, marital status, religion, occupation, tribe, place of the interview, the respondents' premorbid pattern of help-seeking for medical service and the premorbid utilization of breast cancer screening modalities

\begin{tabular}{|c|c|c|c|}
\hline \multicolumn{4}{|l|}{ a. Demographic characteristics } \\
\hline Age Distribution & $n(\%)$ & Marital Status & $n(\%)$ \\
\hline $21-30$ & $16(3.8)$ & married & $285(68)$ \\
\hline $31-40$ & $92(22)$ & widow & $48(11.5)$ \\
\hline $41-50$ & $119(28.2)$ & single & $23(5.5)$ \\
\hline $51-60$ & $92(22)$ & separated/divorced & $7(1.7)$ \\
\hline $61-70$ & $50(12)$ & unspecified & $57(13.3)$ \\
\hline $71-80$ & $32(7.6)$ & & \\
\hline$>80$ & $7(1.6)$ & Religion & \\
\hline unspecified & $12(2.8)$ & christian & $296(70.5)$ \\
\hline mean: $50.6 \pm 13.6$ years, & & muslim & $113(27)$ \\
\hline Median: 49 (IQR 40-60 years) & & unspecified & $11(2.5)$ \\
\hline Educational Status & & Tribe & \\
\hline tertiary & $144(34.3)$ & yoruba & $412(98)$ \\
\hline secondary & $124(29.5)$ & others & $8.0(2.0)$ \\
\hline primary & $66(15.7)$ & & \\
\hline none & 79 (18.8) & Place of Interview & \\
\hline \multirow[t]{2}{*}{ unspecified } & $7(1.7)$ & southwest & $279(66 \%)$ \\
\hline & & northcentral & $141(34)$ \\
\hline Premorbid Help-seeking & $n(\%)$ & Use of SBE & $n(\%)$ \\
\hline self-medication & $139(33.1)$ & daily & $25(6.0)$ \\
\hline visit doctor/nurse/CHEW & $139(33.1)$ & weekly & $10(1.0)$ \\
\hline visit chemist/pharmacist & $45(10.7)$ & monthly & $29(7.0)$ \\
\hline Alternative care & $29(6.9)$ & occasionally & $60(14)$ \\
\hline observe/tell relation & $6(1.4)$ & Not perform & $296(72)$ \\
\hline unspecified & $62(14.8)$ & & \\
\hline The pattern of Symptom Detection & & Exposure to CBE, Mammo or USS & \\
\hline Inadvertent & $404(96)$ & yes & $16(4)$ \\
\hline During SBE or walk-in screening & $10(2.5)$ & no & $404(96)$ \\
\hline Pain drew attention & $4(1.0$ & & \\
\hline Husband detected & $2(0.5)$ & Aware of Breast Cancer & \\
\hline First Healthcare Provider & $n(\%)$ & yes & $289(68.8)$ \\
\hline doctor & $301(71.7)$ & no & $108(25.7)$ \\
\hline nurse & $55(13.1)$ & unspecified & $23(5.5)$ \\
\hline chemist/pharmacist & $26(6.2)$ & & \\
\hline breast surgeon & $25(6.0)$ & & \\
\hline CHEW & $6.0(1.4)$ & & \\
\hline others & $3(0.7)$ & & \\
\hline unspecified & $4(1.0)$ & & \\
\hline
\end{tabular}

CHEW community health extension worker, CBE clinical breast examination, Mammo mammography, SBE self breast exam, USS ultrasound scan, IQR interquartile range

The Demographic characteristics of respondents showing age distribution, educational status, marital status, religion, occupation, tribe, place of the interview, the respondents' premorbid pattern of help-seeking for medical service and the premorbid utilization of breast cancer screening modalities 
Table 2 Showing the cumulative number of respondents with increasing time segments in the intervals: Most respondents disclosed early and consulted FHP early. Most respondents had a long primary-care interval and an extended detection to specialist interval

\begin{tabular}{|c|c|c|c|c|c|c|c|c|c|}
\hline \multicolumn{10}{|c|}{ Results of time spent by respondents in the intervals } \\
\hline Interval in days & $\begin{array}{l}1-7 \\
(\%)\end{array}$ & $\begin{array}{l}1-14 \\
(\%) \\
\end{array}$ & $\begin{array}{l}1-30 \\
(\%) \\
\end{array}$ & $\begin{array}{l}1-60 \\
(\%)\end{array}$ & $\begin{array}{l}1-90 \\
(\%) \\
\end{array}$ & Mean & Median & Range & IQR \\
\hline appraisal $(n=407)$ & $\begin{array}{l}250 \\
(61)\end{array}$ & $\begin{array}{l}285 \\
(70)\end{array}$ & $\begin{array}{l}330 \\
(81)\end{array}$ & $\begin{array}{l}346 \\
(85)\end{array}$ & $\begin{array}{l}366 \\
(90)\end{array}$ & $44 \pm 131$ & 6.0 & $1-1469$ & $1-28$ \\
\hline $\begin{array}{l}\text { help-seeking } \\
(n=397)\end{array}$ & $\begin{array}{l}105 \\
(26)\end{array}$ & $\begin{array}{l}139 \\
(35)\end{array}$ & $\begin{array}{l}196 \\
(50)\end{array}$ & $\begin{array}{l}230 \\
(58)\end{array}$ & $\begin{array}{l}273 \\
(68)\end{array}$ & $114 \pm 202$ & 42 & $1-2190$ & $7-150$ \\
\hline $\begin{array}{l}\text { primary-care } \\
(n=371)\end{array}$ & $\begin{array}{l}91 \\
(25)\end{array}$ & $\begin{array}{l}95 \\
(26)\end{array}$ & $\begin{array}{l}134 \\
(36)\end{array}$ & $\begin{array}{l}167 \\
(42)\end{array}$ & $\begin{array}{l}190 \\
(48)\end{array}$ & $256 \pm 377$ & 106 & $1-2176$ & $13-337$ \\
\hline detection-to-specialist $(n=401)$ & $\begin{array}{l}16 \\
(4)\end{array}$ & $\begin{array}{l}26 \\
(6)\end{array}$ & $\begin{array}{l}48 \\
(12)\end{array}$ & $\begin{array}{l}83 \\
(20)\end{array}$ & $\begin{array}{l}108 \\
(26)\end{array}$ & $363 \pm 409$ & 240 & $1-2300$ & $90-372$ \\
\hline
\end{tabular}

Showing the cumulative number of respondents with increasing time segments in the intervals: Showing the cumulative number of respondents with increasing time segments in the intervals: Most respondents disclosed early and consulted FHP early. Most respondents had a long primary-care interval and an extended detection to specialist interval

tandem with the advice received within 2 weeks. Patronizing orthodox care, being married, and being younger were associated with early disclosure (Table 4) in the unadjusted logistic regression analysis. In the adjusted analysis combining age, premorbid preference, and marital status to predict early disclosure, only premorbid preference and marital status were significant.

\section{Patterns of FHP attendance and factors influencing HSI}

Most respondents (355 of 417(85 95\% CI 81-88) first sought orthodox medical care. The most common FHP was a general practitioner (Table 1). A total of 63 (15\% (95\% CI 12-19) first sought alternative care. The majority of respondents who were hospital goers before detecting their breast symptom still visited a hospital first for treatment (275 of 323 (85 95\% CI 81-89). The odds of visiting hospital first vs. switching to alternative care was 2.3 (1.0-5.1) among this subgroup of patients.

Receiving correct advice(asking the patient to visit a hospital, to visit orthodox healthcare provider, or go for investigation) from person1 and patronizing hospital for other illnesses were both associated with short HSI (Table 4). There was a weak correlation between the length of API and the length of the help-seeking interval.

$$
r=0.13(95 \% \text { CI } 0.03-0.23)
$$

\section{Factors influencing the length of the $\mathrm{PCl}$}

More respondents with big $(>5 \mathrm{~cm})$ tumors received correct advice compared to those with small tumors (Risk difference 5.5\% (95\% CI 4.0-15). The probability of correct advice was higher among the doctor FHP compared to nondoctor FHP (Risk difference 8.4 (95\% CI 3.2, 20). In the unadjusted analysis, receiving correct advice and having a big tumor were associated with short PCI. Only receiving correct advice was significant in the adjusted odds ratio (AOR) (Table 4).

\section{Relationship between the component intervals and the $\mathrm{SCl}$}

The PCI strongly correlated with the SCI $(r=0.9,95 \%$ CI 0.88-0.92). Other intervals correlated weakly with the SCI. (API $r=0.395 \%$ CI $0.22-0.40$ and HSI $r=0.38$, 95\% CI 0.30-0.47).

There was a high probability of having a short SCI after traversing any component interval quickly (Table 5). The odds ratio (OR) for a short SCI vs. long SCI among those who had short API was 6.5 (95\% CI 2.6-16.7), among those who had short help-seeking was 11 (95\% CI 5.4-2.1) and among those who had short primarycare was 8.3 (95\% CI 5.0-14).

Among those who divulged reasons for the long helpseeking intervals, symptom misinterpretation or symptom accumulation was 92 (47\%), socioeconomic reasons were 47 (24\%), and ignorance was 6 (3.0\%). Reasons for long primary-care intervals was misdiagnosis by a health care provider in 37 (25\%) (Table 6).

\section{Impact of interval length on the tumor size and risk of T- category progression}

The self-reported tumor size of 13 patients among the 420 records were unreliable and excluded from the analysis of the growth in tumor size and risk of tumor size progression. Most tumors were estimated as early $\mathrm{T}$ category at detection, whereas most were locally advanced at the specialist clinic (Table 7). Mean difference in $\mathrm{T}$-size was significant(. paired t-test mean difference $5.0 \pm 4.9 \mathrm{~cm}$ (95\% CI 4-5), median 3.0 vs. 8.0 WilcoxonSigned Rank test $P=0.0001)$.

There was a moderate correlation between the length of the total interval and the growth in tumor size $(\mathrm{r}=$ $0.4)$. The average growth in the tumor size per month 
Table 3 Showing the distribution of the first person(person1) the respondents informed about their breast symptom(s), the pattern of directives received from the first person(Person1), the first orthodox medical personnel, the number of persons informed and number of personnel visited

\begin{tabular}{|c|c|c|c|}
\hline \multicolumn{4}{|l|}{ a. Distribution of the first person informed } \\
\hline Person1 informed $(N=419)$ & & $n(\%)$ & \\
\hline husband & & $212(50.6)$ & \\
\hline \multirow[t]{3}{*}{ child } & Unspecified child & $47(11.1)$ & \\
\hline & son & $9(2)$ & \\
\hline & daughter & $6(1.4)$ & \\
\hline \multirow[t]{3}{*}{ sibling } & Unspecified sibling & $3(0.7)$ & \\
\hline & male & $6(1.4)$ & \\
\hline & female & $31(7.6)$ & \\
\hline \multirow[t]{3}{*}{ parent } & Unspecified parent & $2(0.4)$ & \\
\hline & father & $2(0.4)$ & \\
\hline & mother & $20(5.0)$ & \\
\hline extended family/in-laws & & $6(1.4)$ & \\
\hline \multirow[t]{2}{*}{ unrelated persons } & friends/co-worker & $15(3.7)$ & \\
\hline & neighbor & $4(0.8)$ & \\
\hline doctor & & $24(6.0)$ & \\
\hline \multirow[t]{2}{*}{ nursing personnel } & CHEW & $3(0.6)$ & \\
\hline & Certified nurse & $17(4.0)$ & \\
\hline chemist/pharmacist & & $3(0.8)$ & \\
\hline spiritual leader & & $9(2.0)$ & \\
\hline \multicolumn{4}{|l|}{ b, Advice received from person 1 or FHP } \\
\hline Advice from first person & $n(\%)$ & Advice from FHP & $n(\%)$ \\
\hline visit general practitioner & $215(55)$ & Visit doctor & $17(5.5)$ \\
\hline Visit a breast surgeon & $11(2.9)$ & Visit surgeon & $139(44.8)$ \\
\hline Visit nurse & $6(1.6)$ & investigate & 129 (41.6) \\
\hline Investigate & $13(3.2)$ & Antibiotics/injection/gel & $5(1.6)$ \\
\hline Antibiotics/ gel & $12(3.0)$ & consult spiritual leader & $3(1.0)$ \\
\hline chemist or pharmacist & $9(2.5)$ & observe/reassured & $17(5.5)$ \\
\hline Excise & $5(1.5)$ & & \\
\hline Alternative & $40(11)$ & & \\
\hline Observe/Reassured/tell & $48(12)$ & & \\
\hline Go hospital & $24(6.0)$ & & \\
\hline People informed(range 0-11, median: 2) & & Number of FHP visited(range: $0-4$, median: 1) & \\
\hline $0-1$ & $152(37)$ & $0-1$ & $296(73)$ \\
\hline $2-3$ & $170(42)$ & $2-3$ & $107(26)$ \\
\hline$>3$ & $86(21)$ & $>3$ & $4(1.0)$ \\
\hline
\end{tabular}

CHEW community health extension worker, FHP First Healthcare Provider

Table showing the distribution of the first person(Primary person) the respondents informed about their breast symptom(s), the pattern of directives received from the first person(Primary person), the first orthodox medical personnel, the number of persons informed and number of personnel visited

was estimated to be $0.4 \mathrm{~cm}$ in the first 12 months. The risk of tumor progression within the first 12 months was lowest in the first month (Table 7). The overall risk that a lump would be locally advanced when detected inadvertently was $12 \%$ (95\% CI 9-16), and the risk that it would migrate to the next $\mathrm{T}$-category before arriving in a specialist clinic was $64 \%$ (95\% CI 59-69). The OR for T-category progression in SC interval of 31-90 days vs. $1-30$ days was 5 (95\% CI 2.0-12), and the OR in SC interval $>90$ days vs. $1-30$ days was 16 (95\% CI 7.0-38). Among patients who detected their tumors relatively early (estimated as T1 or T2), the hazard of progressing 
Table 4 Showing the probability of short appraisal or short help-seeking interval based on the specific sociodemographic characteristics, the premorbid exposure, and experience(s) after disclosure and during help-seeking

\begin{tabular}{|c|c|c|c|c|c|c|c|}
\hline Variable & $\mathrm{N}$ & $\begin{array}{l}\text { Probability of short } \\
\text { appraisal(\%) }\end{array}$ & $P$ value & Variable & $N$ & $\begin{array}{l}\text { Probability of short } \\
\text { help-seeking (\%) }\end{array}$ & - \\
\hline \multicolumn{3}{|l|}{ Age bracket } & \multirow[t]{4}{*}{0.02} & \multicolumn{3}{|l|}{ Age bracket } & \multirow[t]{4}{*}{0.36} \\
\hline $20-40$ & 144 & 82 & & $20-40$ & 112 & 56 & \\
\hline $41-60$ & 207 & 85 & & $41-60$ & 204 & 61 & \\
\hline$>60$ & 85 & 71 & & $>60$ & 80 & 52 & \\
\hline \multicolumn{4}{|l|}{ Education } & \multicolumn{3}{|l|}{ Education } & \multirow[t]{5}{*}{0.15} \\
\hline none & 76 & 76 & \multirow[t]{4}{*}{0.56} & none & 70 & 47 & \\
\hline primary & 62 & 79 & & primary & 63 & 57 & \\
\hline secondary & 122 & 80 & & secondary & 115 & 57 & \\
\hline tertiary & 140 & 86 & & tertiary & 136 & 65 & \\
\hline \multicolumn{3}{|l|}{ Marital status } & \multirow[t]{5}{*}{0.03} & Marital status & & & \multirow[t]{5}{*}{0.06} \\
\hline married & 276 & 85 & & married & 269 & 58 & \\
\hline single & 23 & 65 & & single & 22 & 36 & \\
\hline divorced/separated & 57 & 67 & & divorced/separated & 9 & 50 & \\
\hline widow & 47 & 70 & & widow & & 61 & \\
\hline \multicolumn{3}{|l|}{ Awareness } & \multirow[t]{3}{*}{0.36} & Awareness & & & \multirow[t]{3}{*}{0.08} \\
\hline aware of $B C$ & 281 & 83 & & aware of $B C$ & 271 & 61 & \\
\hline unaware of $B C$ & 106 & 77 & & unaware of $B C$ & 104 & 57 & \\
\hline \multicolumn{3}{|l|}{$\begin{array}{l}\text { Premorbid health service } \\
\text { preference }\end{array}$} & \multirow[t]{4}{*}{0.02} & $\begin{array}{l}\text { Premorbid health service } \\
\text { preference }\end{array}$ & & & \multirow[t]{4}{*}{0.01} \\
\hline hospital(doc/nurse) & 80 & 84 & & hospital(doc/nurse) & 178 & 65 & \\
\hline self-medicate & 137 & 82 & & self-medicate & 131 & 52 & \\
\hline alternative & 33 & 64 & & alternative & 33 & 36 & \\
\hline \multicolumn{3}{|l|}{ Tumor size at detection } & \multirow[t]{6}{*}{0.56} & Tumor size at detection & & & \multirow[t]{3}{*}{0.12} \\
\hline $1-5 \mathrm{~cm}$ & 345 & 81 & & $1-5 \mathrm{~cm}$ & 341 & 57 & \\
\hline \multirow[t]{4}{*}{$>5 \mathrm{~cm}$} & 48 & 81 & & $>5 \mathrm{~cm}$ & 45 & 64 & \\
\hline & & & & Person 1 advice & & & 0.02 \\
\hline & & & & correct & 252 & 63 & \\
\hline & & & & incorrect & 107 & 48 & \\
\hline \multicolumn{4}{|c|}{ Association with short Appraisal } & \multicolumn{4}{|c|}{ Association with short Help-seeking interval } \\
\hline & & OR & $\mathrm{AOR}$ & & & OR & $\mathrm{AOR}$ \\
\hline$>60$ & & 1 & & Incorrect advice & & 1 & \\
\hline $41-60$ & & $2.3(1.3-4.2)$ & $1.3(0.6-3.0)$ & Correct advice & & $1.9(1.2-3.0)$ & $1.7(1.1-3.0)$ \\
\hline \multirow[t]{2}{*}{$\leq 40$} & & $2.0(1.3-3.8)$ & $2.0(0.9-4.4)$ & & & & \\
\hline & & & & alternative & & 1 & \\
\hline not in relationship & & 1 & & Self-medicate & & $1.9(0.9-4.1)$ & $1.5(0.7-3.6)$ \\
\hline married & & $2.6(1.4-4.6)$ & $2.1(1.1-4.2)$ & Hospital goer & & $3.2(1.5-7.1)$ & $2.5(1.1-5.9)$ \\
\hline alternative & & 1 & & Association with short Pri & $y$-care & erval & \\
\hline self-medicates & & $2.6(1.1-5.9)$ & $2.3(0.8-5.9)$ & & & OR & $\mathrm{AOR}$ \\
\hline hospital goer & & $3.0(1.3-6.7)$ & $3.1(1.2-8.1)$ & small tumor & & 1 & \\
\hline & & & & big tumor & & $1.6(1.0-2.4)$ & $0.7(0.4-1.2)$ \\
\hline & & & & incorrect advice & & 1 & \\
\hline & & & & correct advice & & $2.1(1.2-3.9)$ & $2.0(1.1-3.5)$ \\
\hline
\end{tabular}

Table showing the probability of short appraisal or short help-seeking interval based on the specific sociodemographic characteristics, the premorbid exposure, and experience(s) after disclosure and during help-seeking 
to advanced-stage increased with time. The hazard was lowest in the first 30 days (3\%), $17 \%$ in 60 days, $31 \%$ in 90 days and $61 \%$ in 180 days.

\section{Discussion}

In this survey, two-thirds of the respondents stayed longer than three months between detecting $\mathrm{BC}$ symptoms and arriving in a specialist clinic. The PCI was the longest interval, and there was a strong correlation between the length of the PCI and the SCI. Symptom misinterpretation and misdiagnosis were frequent reasons for extended intervals. The majority of the patient detected their lesion early, but the majority were already locally advanced before arriving in a specialist clinic.

At least two-thirds of our respondents first visited orthodox personnel to seek help and, a similar proportion consulted FHP early in tandem with their advisor's directives. We did not establish the direct influence of advisors on the women's decision nonetheless, the association is consistent with the report in South Africa [16], where patients acted based on pressure from relations. The husbands were the most frequent advisors; hence, they are a potential focus for intervention. Engaging men to promote uptake of positive breast health activities is useful in places where women rely on husband and family support [20], notably, in Africa, where the men dominate the leadership role [21] and politics.

Similar to previous reports in Nigeria, $[9,22]$ a large number of our respondents preferred orthodox care, and the pattern of help-seeking was consistent with their premorbid preference for health care services. This indicates that without unfavorable experience(s), it is unlikely that women will suddenly change their health care preferences once they detected their breast lesions. We can exploit the premorbid conditioning by improving access to our hospitals. Raising satisfaction derived in the hospital for treatment of other minor illnesses might build confidence and enduring relationship between potential breast cancer patients and the clinicians.

The longer PCI and its dominating influence compared to the other intervals supports some reports and negates others. Harirchi in Tehran [23] and Yau et al. in Hong Kong [24] reported a higher proportion of patients with help-seeking delay. Moodley et al. first reported a higher proportion of delay in the patient interval among 20 patients in South Africa [16] and then in a subsequent study of 201 patients; they reported a higher proportion of long delays in the system's interval [25]. Roy et al. [26] in Bangladesh and Maghous et al. [27] in Morocco, both reported that doctors were complicit in a third of long interval situations [26, 27]. Also, in Nigeria, Ezeome et al. [9], Ayoade et al. [17] and Akinkuolie et al. [20] reported disease progression during the primary-care interval.
The most frequent reason for a long primary-care interval in this study was misdiagnosis by the FHP. We found that smaller tumors were associated with longer intervals. We suspect that smaller tumors were more challenging to evaluate because of limited symptomatology. Instances of symptom misinterpretation and misdiagnosis were also prominent reasons for extended intervals in other studies in Nigeria [4, 28], other parts of Africa [16, 27, 29-31], middle east [32] and Asia [28], Ensuring triple assessment rather than depend on physical finding to initiate treatment may reduce misdiagnosis. In our study, the risk of incorrect advice was higher among nondoctor FHP compared to doctor FHP. The doctor FHP and nondoctor FHP had different error patterns, which should be noted during education campaigns.

We found that there is an increasing probability of transitioning from early to locally advanced disease as time elapsed, and the risk of transitioning was least in the first 30 days after the detection of early disease, and it more than doubled afterward. One out of every ten women who detected their lumps inadvertently were already locally advanced. Furthermore, one out of every three was likely to be advanced among those who arrived in a specialist clinic after 30 days. This suggests that the strategy to promote early detection and treatment of clinically symptomatic BC in low resource settings [33, 34] may be effective in our patients if implemented with a tight timeline. Although we could not assess the influence of tumor biology on disease progression in this study and we assumed that time was an independent predictor of tumor progression, the common timeline in our literature describing detection to presentation of more than three months as late $[9,17,27]$ was lax for this cohort of respondents because at least a third already experienced significant tumor growth within 90 days.

The clinical implication of for long detection to treatment interval is not adequately researched in Africa. In a population of BC patients in southern Africa [18], more than $20 \%$ were locally advanced in a median time to treatment of 110 days. In Ghana [35], patients who stayed a total interval shorter than 2 months had smaller tumors compared to the total interval of 12 months. In contrast, two-thirds of patients who stayed longer than six months in a study in Uganda [36] still had an early disease. We need more studies to describe the relationship between total interval and outcome in Africans.

Our study is the first to explicitly show the relationship between premorbid experience and the pattern of help-seeking among breast cancer patients in subSaharan Africa. Our study is also the first to show the likely changes in breast tumor size as time elapsed in a cohort of breast cancer patients in sub-Saharan Africa and the first to show the relationship between the 
Table 5 Showing the probability of short primary-care and symptom-detection to specialist interval based on specific sociodemographic risk factors, premorbid exposure and the experience(s) after disclosure and during help-seeking

\begin{tabular}{|c|c|c|c|c|c|c|c|}
\hline Variable & $\mathrm{N}$ & $\begin{array}{l}\text { Probability of short } \\
\text { Primary-care(\%) }\end{array}$ & $P$ value & Variable & N & $\begin{array}{l}\text { Probability of short } \\
\text { total interval (\%) }\end{array}$ & $P$ value \\
\hline Age bracket & & & 0.11 & Appraisal interval & & & 0.001 \\
\hline $20-40$ & 102 & 29 & & short & 314 & 31 & \\
\hline $41-60$ & 189 & 32 & & long & 75 & 7 & \\
\hline$>60$ & 79 & 43 & & Help-seeking interval & & & 0.001 \\
\hline Education & & & & short & 221 & 41 & \\
\hline none & 73 & 40 & 0.09 & long & 160 & 7 & \\
\hline primary & 61 & 26 & & Primary-care interval & 63 & & 0.001 \\
\hline secondary & 106 & 35 & & short & 124 & 52 & \\
\hline tertiary & 124 & 30 & & long & 247 & 12 & \\
\hline Marital status & & & 0.60 & & & & \\
\hline married & 254 & 34 & & & & & \\
\hline single & 20 & 40 & & Incorrect advice & & & \\
\hline divorced/separated & 8 & 50 & & Doctors(GP) & & & \\
\hline widow & 45 & 33 & & Antibiotics/gel & 19 & & \\
\hline Awareness of $\mathrm{CaB}$ & & & 0.16 & excise & 29 & & \\
\hline aware & 252 & 31 & & Observe/reassure & 4 & & \\
\hline unaware & 98 & 37 & & & & & \\
\hline Premorbid health service preference & & & 0.34 & Nurse/CHEW & & & \\
\hline hospital care(doc/nurse) & 166 & 37 & & Antibiotics/gel & 13 & & \\
\hline self-medicate & 122 & 34 & & excise & 2 & & \\
\hline alternative & 33 & 24 & & observe & 2 & & \\
\hline Tumor size at arrival at primary-care & & & 0.03 & Chemist/pharmacist & & & \\
\hline $1-5 \mathrm{~cm}$ & 211 & 29 & & antibiotics/gel & 9 & & \\
\hline$>5 \mathrm{~cm}$ & 147 & 39 & & excise & 1 & & \\
\hline Personnel advice & & & 0.02 & & & & \\
\hline correct & 257 & 37 & & & & & \\
\hline incorrect & 76 & 20 & & & & & \\
\hline No of personnel visited & & & 0.17 & & & & \\
\hline $0-1$ & 260 & 36 & & & & & \\
\hline$>1$ & 100 & 28 & & & & & \\
\hline $\begin{array}{l}\text { Correct advice in subgroups } \\
\text { of respondents }\end{array}$ & $n$ & $\begin{array}{l}\text { Probability of correct } \\
\text { advice(\%) }\end{array}$ & & & & & \\
\hline big tumor $(>5 \mathrm{~cm})$ & 143 & 75 & & & & & \\
\hline small tumor $(\leq 5 \mathrm{~cm})$ & 222 & 69 & & & & & \\
\hline$\leq 40$ years $n=104$ & 104 & 78 & & & & & \\
\hline $41-60$ years $n=194$ & 194 & 70 & & & & & \\
\hline$>60$ years $n=78$ & 78 & 76 & & & & & \\
\hline doctor FHP & 292 & 69 & 0.17 & & & & \\
\hline nondoctor FHP & 86 & 40 & & & & & \\
\hline
\end{tabular}

Table showing the probability of short primary-care and symptom-detection to specialist interval based on specific sociodemographic risk factors, premorbid exposure, and the experience(s) after disclosure and during help-seeking 
Table 6 shows the reasons reported for long help-seeking intervals (> 60 days) or long primary-care intervals(> 30 days) by respondents

\begin{tabular}{|c|c|c|}
\hline $\begin{array}{l}\text { Reason for help-seeking interval }>60 \\
\text { days or Primary-care interval }>30 \text { days }\end{array}$ & $\begin{array}{l}\text { Help-seeking, } \\
\mathrm{n}-172(\%)\end{array}$ & $\begin{array}{l}\text { Primary-care, } \\
n=167(\%)\end{array}$ \\
\hline \multicolumn{3}{|c|}{ Symptom misinterpretation/symptom accumulation/misdiagnosis } \\
\hline ignorance & $6(3.5)$ & \\
\hline pregnancy/lactation/menopause & $8(4.6)$ & $1.0(0.6)$ \\
\hline thought benign/though will disappear & $50(29)$ & $22(13.0)$ \\
\hline small size & $2(1.2)$ & \\
\hline lump only & $2(1.2)$ & \\
\hline no pain & $19(11)$ & $12(7.0)$ \\
\hline thought boil/using antibiotics & $15(8.7)$ & $1.0(0.6)$ \\
\hline thought ringworm/skin change only & $1.0(0.6))$ & \\
\hline Navigation in primary care & & $1.0(0.6)$ \\
\hline Misdiagnosis/Investigations & & $46(27.5)$ \\
\hline \multicolumn{3}{|l|}{ Socioeconomic } \\
\hline busy schedule & $3.0(1.7)$ & \\
\hline financial constraint & $18(10.5)$ & $33(19.7)$ \\
\hline family issues & $2.0(1.2)$ & $2.0(1.2)$ \\
\hline distance & $3.0(1.7)$ & \\
\hline secrecy & $1.0(0.6)$ & \\
\hline spiritual & $10(5.8)$ & $4.0(2.4)$ \\
\hline herbal care & $10(5.8)$ & $7.0(4.2)$ \\
\hline \multicolumn{3}{|l|}{ Others } \\
\hline reassured & $7.0(4.0)$ & $7.0(4.2)$ \\
\hline strike & $4.0(2.4)$ & $8.0(4.7)$ \\
\hline fear of diagnosis/panic & $5.0(2.9)$ & $16(9.5)$ \\
\hline fear of mastectomy & $6.0(3.5)$ & $6.0(3.5)$ \\
\hline mistrust orthodox & & $2.0(1.2)$ \\
\hline
\end{tabular}

component intervals and their relative influence on the time to a specialist clinic.

This research is limited in that the primary outcome was patient-reported; hence it might be influenced by recall bias. We attempted to minimize the bias by interviewing the patients within four weeks of arriving in the specialist clinic. Moreover, we helped them to cast their minds back on significant events occurring around the recalled dates or periods.

The self-reported tumor size based on patients' retrospective recall may be inaccurate, and we could not triangulate for its accuracy by comparing the respondent's recall with the primary-care records due to poor recordkeeping. Also, we did not evaluate the interaction between tumor biology, the elapsed time, and tumor progression. We were unable to find other ways of estimating tumor size at detection because it was a prehospital event, and we were unable to find other ways of estimating tumor size at contact with the FHP. Nonetheless, we attempted to minimize inconsistency in the self-reported tumor size by using the estimate given by the patient at all points for the analysis, and we excluded overtly inaccurate estimates.

\section{Conclusion}

Most patients in this study visited the FHP early; however, most stayed longer than 3 months between symptom detection and arriving in a specialist clinic with significant tumor progression in the interval. The PCI was the longest interval. The most common reasons for long intervals were symptom misinterpretation and system-related factors.

Table 7 Showing tumor size at various time segments in the continuum from detection to specialist clinic. Also, showing the risk of progression in tumor size per time segment

\begin{tabular}{|c|c|c|c|c|c|c|c|c|}
\hline \multirow[b]{2}{*}{$\begin{array}{l}\text { Interval } \\
\text { Length } \\
\text { (days) }\end{array}$} & \multicolumn{3}{|c|}{ Variables at detection } & \multicolumn{5}{|c|}{ Variable at specialist clinics } \\
\hline & $\begin{array}{l}\text { Mean } \\
\text { T-size } \\
(\mathrm{cm})\end{array}$ & $\begin{array}{l}\text { Median } \\
\text { T-size } \\
(\mathrm{cm})\end{array}$ & IQR & $\begin{array}{l}\text { Mean } \\
\text { T-size } \\
(\mathrm{cm})\end{array}$ & $\begin{array}{l}\text { Median } \\
\text { T-size } \\
(\mathrm{cm})\end{array}$ & $\begin{array}{l}\text { T-size } \\
\text { IQR } \\
(\mathrm{cm})\end{array}$ & $\begin{array}{l}\text { "Risk of } \\
\text { T-stage migration } \\
\text { (\% with } 95 \% \mathrm{Cl} \text { ) }\end{array}$ & $\begin{array}{l}\text { *Risk of locally advanced } \\
\text { disease at arrival in SC } \\
(95 \% \mathrm{Cl})\end{array}$ \\
\hline $\begin{array}{l}1-30 \\
N=47\end{array}$ & $4.0 \pm 2.0$ & 4.0 & $2.0-5.0$ & $5 \pm 3$ & 4.0 & $4.0-6.0$ & $19(8-40)$ & $\begin{array}{l}17(6-33) \\
N=36\end{array}$ \\
\hline $\begin{array}{l}31-90 \\
N=58\end{array}$ & $4.0 \pm 2.0$ & 4.0 & $3.0-4.0$ & $7 \pm 4$ & 6.0 & $4.0-8.0$ & $54(39-68)$ & $\begin{array}{l}46(32-61) \\
N=50\end{array}$ \\
\hline $\begin{array}{l}>90 \\
N=296\end{array}$ & $4.0 \pm 2.0$ & 3.0 & $2.0-4.0$ & $9 \pm 5$ & 8.0 & $6.0-10.0$ & $76(78-89)$ & $\begin{array}{l}74(68-80 \\
N=170\end{array}$ \\
\hline T-size & \multicolumn{3}{|c|}{ number at detection } & \multicolumn{5}{|c|}{ the number at the specialist clinic } \\
\hline $\mathrm{T} 1$ & \multicolumn{3}{|l|}{$162(40 \%)$} & \multicolumn{5}{|c|}{$32(8 \%)$} \\
\hline $\mathrm{T} 2$ & \multicolumn{3}{|l|}{$192(47 \%)$} & \multicolumn{5}{|c|}{$99(24 \%)$} \\
\hline T3 & \multicolumn{3}{|l|}{$50(13 \%)$} & \multicolumn{5}{|c|}{$278(68 \%)$} \\
\hline Mean & \multicolumn{3}{|c|}{$3.0 \pm 2.0 \mathrm{~cm}$} & \multicolumn{5}{|c|}{$8.0 \pm 5.0 \mathrm{~cm}$} \\
\hline
\end{tabular}

arisk of migration to locally advanced among respondents whose disease was early at detection (i.e., risk of migrating from T1 to T3 or from T2 to T3). \# risk of migration to the next T- stage (i.e., risk of migration from T1 to T2 or from T2 to T3)

NB. The records of respondents who had tumors $>5 \mathrm{~cm}$ at detection were excluded from the analysis of stage migration since we would be unable to observe further stage migration according to the tumor size staging using the AJCC 7th edition 


\section{Supplementary information}

Supplementary information accompanies this paper at https://doi.org/10. 1186/s12889-020-09074-W.

\section{Additional file 1. Data collection questionnaire.}

\section{Abbreviations}

API: Appraisal interval; AOR: Adjustted odds ratio; AJCC: American Joint Committtee on Cancer; BC: Breast cancer; BSE: Breast self-Examination; CBE: Clinical breast examination; Cl: Confidence interval; CHEW: Community health extension worker; FHP: First healthcare provider; HIS: Help-seeking interval; IQR: Interquartile range; LMICs: Low and middle income countries; Mammo: Mammography; NS: Not significant; OR: Odds ratio; PCl: Primary care interval; r: Correlation coefficient; SCl: Symptom detection to specialist interal; T: Tumor size

\section{Acknowledgements}

We thank Prof Peter Kingham of Memorial Sloan Kettering Cancer Center, the United States of America and Dr. Isaac Alatise of Obafemi Awolowo University Teaching Hospital Complex, Nigeria for their support throughout the project.

\section{Disclosure}

This is the concluding report of the cross-sectional phase of a robust research endeavor to find the drivers of late presentation and poor outcome of breast cancer in Southwestern and Northcentral Nigeria. The research group published a preliminary report of first one hundred respondents [37] and a report on the different clusters of presentation and impact of events in the primary-care interval in response to the observed scanty report about the system interval and influence of primary-care practitioners in Nigeria [38]. This report presents findings on the primary hypothesis of the cross-sectional phase detailing the factors influencing the pathway to the specialist and the impact of delay on disease migration.

\section{Authors' contributions}

$\mathrm{AO}, \mathrm{RG}, \mathrm{OS}, \mathrm{AH}$ jointly conceived the research. $\mathrm{AO}, \mathrm{OSA}, \mathrm{OK}, \mathrm{OJ}, \mathrm{OS}, \mathrm{KA} F \mathrm{O}, \mathrm{HO}$, $A S, A J, A B$ recruited respondents and collected data, EA. Administration of the project was by AO. Statistical analysis was by $A O, G A$ and OS. Writing and original draft was by $\mathrm{AO}, \mathrm{GA}, \mathrm{OK}, \mathrm{OS}, \mathrm{AJ}$ and $\mathrm{OJ}$. All authors were involved in extensive formative review and editing. All authors approved the final manuscript

\section{Funding}

The African Research Group for Oncology funded this research. The funding body had no role in the design, data collection, analysis, interpretation and write up of the manuscript.

\section{Availability of data and materials}

Data limited for interpreation of results for this research is available on reasonable request to the corresponding author and as supplementary file.

\section{Ethics approval and consent to participate}

Ethical approval was obtained from the ethical review committee of the University of Ilorin Teaching Hospital Ilorin(Oke-Ose, Esie, Offa) (ERCPAN/ 2017/02/1644). Concurrent approval was obtained from other participating centers namely; Ekiti state teaching hospital(EKSUTH/A67/2017/05/010, LAUTECH Osogbo and Ogbomoso (LTH/REC/2017/06/10/368, Federal Medical Center Owo (FMC/OW/380NOL LXVII/67, Federal Medical Center Ido (ERC/2018/114/03/6213), and General Hospital Ilorin (Surulere and Sobi)(GHI/ ADM/134/NOL.1/62). All respondents consented to the study and gave written informed consent after detailed explanation. No personal information, images or video footage was revealed.

\section{Consent for publication}

not applicable.

\section{Competing interests}

the authors declare that there is no competing interest.

\section{Author details}

'Department of Surgery, University of Ilorin and University of Ilorin Teaching Hospital, Ilorin, Kwara state, Nigeria. ${ }^{2}$ Department of Surgery, University of Cape Coast and Cape Coast Teaching Hospital, Cape Coast, Ghana.

${ }^{3}$ Department of Surgery, Ekiti State Teaching Hospital, Ado-Ekiti, Ekiti state, Nigeria. ${ }^{4}$ Department of Surgery, Obafemi Awolowo Teaching Hospital, Ile-Ife, Osun state, Nigeria. ${ }^{5}$ Department of Surgery, Federal Medical Center, Owo, Ondo State, Nigeria. ${ }^{6}$ Department of Surgery, LAUTECH Teaching Hospital, Osogbo, Osun state, Nigeria. ${ }^{7}$ Department of Surgery, University College Hospital, Ibadan, Oyo state, Nigeria. ${ }^{8}$ Department of Surgery, Obafemi Awolowo Teaching Hospital, Ilesha, Osun state, Nigeria. ${ }^{9}$ Department of Surgery, University of Ilorin Teaching Hospital, Ilorin, Kwara state, Nigeria. ${ }^{10}$ Department of Surgery, General Hospital Ilorin, Ilorin, Kwara state, Nigeria.

${ }^{11}$ Department of Radiology, University of Ilorin and University of Ilorin Teaching Hospital, Ilorin, Kwara state, Nigeria. ${ }^{12}$ Department of Surgery, LAUTECH Teaching Hospital, Ogbomoso, Oyo State, Nigeria. ${ }^{13}$ Department of Surgery, Federal Teaching Hospital, Ido-Ekiti, Ekiti state, Nigeria.

Received: 19 January 2020 Accepted: 8 June 2020

Published online: 19 June 2020

\section{References}

1. Jones $\mathrm{CE}$, Maben J, Jack RH, et al. A systematic review of barriers to early presentation and diagnosis with breast cancer among black women. BMJ Open. 2014;4(2):e004076.

2. Agodirin $\mathrm{O}$, Olatoke $\mathrm{S}$, Rahman $\mathrm{G}$, et al. How effective is the treatment of locally advanced and metastatic breast Cancer in developing Centres?: a retrospective review. Ethiop J Health Sci. 2015;25(4):337-44.

3. Pace LE, Mpunga T, Hategekimana $V$, et al. Delays in breast Cancer presentation and diagnosis at two rural Cancer referral centers in Rwanda. Oncologist. 2015;20(7):780-8.

4. Ukwenya AY, Yusufu LM, Nmadu PT, Garba ES, Ahmed A. Delayed treatment of symptomatic breast cancer: the experience from Kaduna, Nigeria. S Afr J Surg Suid-Afrikaanse tydskrif vir chirurgie. 2008;46(4):106-10.

5. Jedy-Agba E, McCormack V, Adebamowo C, dos Santos-Silva I. Stage at diagnosis of breast cancer in sub-Saharan Africa: a systematic review and meta-analysis. Lancet Glob Health. 2016;4(12):e923-35.

6. Sharma K, Costas A, Shulman LN, Meara JG. A systematic review of barriers to breast Cancer Care in Developing Countries Resulting in delayed patient presentation. J Oncol. 2012;2012:121873. https://doi.org/10.1155/2012/ 121873.

7. McKenzie F, Zietsman A, Galukande M, et al. African breast Cancerdisparities in outcomes (ABC-DO): protocol of a multicountry mobile health prospective study of breast cancer survival in sub-Saharan Africa. BMJ Open. 2016;6(8):e011390.

8. da Costa Vieira RA, Biller G, Uemura G, Ruiz CA, Curado MP. Breast cancer screening in developing countries. Clinics (Sao Paulo, Brazil). 2017;72(4):244-53.

9. Ezeome ER. Delays in presentation and treatment of breast cancer in Enugu, Nigeria. Niger J Clin Pract. 2010;13(3):311-6.

10. Pack G, Gallo J. The culpability for delay in the treatment of cancer. Am J Cancer. 1938;33:443-62.

11. Unger-Saldana K, Infante-Castaneda C. Delay of medical care for symptomatic breast cancer: a literature review. Salud publica de Mexico. 2009;51(Suppl 2):s270-85.

12. Dobson CM, Russell AJ, Rubin GP. Patient delay in cancer diagnosis: what do we really mean and can we be more specific? BMC Health Serv Res. 2014;14:387.

13. Weller D, Vedsted P, Rubin G, et al. The Aarhus statement: improving design and reporting of studies on early cancer diagnosis. Br J Cancer. 2012;106(7): 1262-7.

14. Unger-Saldana K. Challenges to the early diagnosis and treatment of breast cancer in developing countries. World J Clin Oncol. 2014;5(3):465-77.

15. Norsa'adah B, Rampal KG, Rahmah MA, Naing NN, Biswal BM. Diagnosis delay of breast cancer and its associated factors in Malaysian women. BMC Cancer. 2011:11:141.

16. Moodley J, Cairncross L, Naiker T, Momberg M. Understanding pathways to breast cancer diagnosis among women in the Western Cape Province, South Africa: a qualitative study. BMJ Open. 2016;6(1).

17. Ayoade B, Salami B, Agboola J, et al. Beliefs and practices associated with late presentation in patients with breast cancer; an observational study of 
patient presenting in a tertiary care facility in Southwest Nigeria. J Afr Cancer. 2015;7(4):178-85.

18. Clegg-Lamptey J, Dakubo J, Attobra YN. Why do breast cancer patients report late or abscond during treatment in Ghana? A pilot study. Ghana Med J. 2009;43(3):127-31.

19. Varela-Centelles P, Lopez-Cedrun JL, Fernandez-Santroman J, et al. Assessment of time intervals in the pathway to oral cancer diagnosis in North-Westerm Spain. Relative contribution of patient interval. Med Oral Patol Oral Cir Bucal. 2017;22(4):e478-e83.

20. Donnelly TT, Al-Khater AH, Al-Bader SB, et al. Perceptions of Arab men regarding female breast cancer screening examinations-Findings from a Middle East study. PLoS One. 2017;12(7).

21. Akinkuolie AA, Etonyeaku AC, Olasehinde O, Arowolo OA, Babalola RN. Breast cancer patients' presentation for oncological treatment: a single Centre study. Pan Afr Med J. 2016:24:63.

22. Olasehinde O, Boutin-Foster C, Alatise OI, et al. Developing a breast Cancer screening program in Nigeria: evaluating current practices, perceptions, and possible barriers. J Glob Oncol. 2017;3(5):490-6.

23. Harirchi I, Karbakhsh M, Hadi F, Madani S, Sirati F, Kolahdoozan S. Patient delay, diagnosis delay and treatment delay for breast cancer: Comparision of the pattern between patients in publi and private health sectors. Arch Breast Cancer. 2015:2(2):15-20.

24. Yau TK, Choi CW, Ng E, Yeung R, Soong IS, Lee AW. Delayed presentation of symptomatic breast cancers in Hong Kong: experience in a public cancer centre. Hong Kong Med J = Xianggang yi xue za zhi. 2010;16(5):373-7.

25. Moodley J, Cairncross L, Naiker T, Constant D. From symptom discovery to treatment - women's pathways to breast cancer care: a cross-sectional study. BMC Cancer. 2018;18(1):312.

26. Chandra Roy B, Naher S, Hanifa M, Sankar P. Pattern of delayed presentation of breast cancer patients: evidence from Rangpur medical college hospital, Rangpu, Bangladesh. Adv Cancer Ransearch Ther. 2015;1 (1):1-6.

27. Maghous $A$, Rais $F$, Ahid $S$, et al. Factors influencing diagnosis delay of advanced breast cancer in Moroccan women. BMC Cancer. 2016;16.

28. Akanbi O, Oguntola S, Adeoti M, Aderounmu A, Idris O, Abayomi O. Delay presentation of breast cancer: a study among south western Nigerian women. Int J Curr Res. 2015;7(8):1-5.

29. Khan M, Shafique S, Khan T, Shahzad M, Iqbal S. Presentation delay in breast cancer patients, identifying the barriers in north Pakistan. Asian Pac J Cancer Prev. 2015;16(1):377-80.

30. Kohler RE, Gopal S, Miller AR, et al. A framework for improving early detection of breast cancer in sub-Saharan Africa: a qualitative study of helpseeking behaviors among Malawian women. Patient Educ Couns. 2017; 100(1):167-73.

31. Mbuka-Ongona D, Tiumbo J. Knowledge about breast cancer and reasons for late presentation by cancer patients seen at Princess Marina Hospital, Gaborone Botswana. Afr J Prim Health Care Fam Med. 2013:5(1):465-76.

32. Elobaid Y, AW TC, Lim JNW, Hamid S, Grivna M. Breast cancer presentation delays among Arab and national women in the UAE: a qualitative study. SSM - population health. 2016;2:155-63.

33. dos Santos SI, McCormack V, Jedy-Agba E, Adebamowo C. Downstaging breast Cancer in sub-Saharan Africa: a realistic target? Cancer Control. 2017:46-52.

34. Yip CH, Smith RA, Anderson BO, et al. Guideline implementation for breast healthcare in low- and middle-income countries: early detection resource allocation. Cancer. 2008;113(8 Suppl):2244-56.

35. Brinton L, Figueroa J, Adjei E, et al. Factors contributing to delays in diagnosis of breast cancers in Ghana, West Africa. Breast Cancer Res Treat. 2017;162(1):105-14.

36. Galukande M, Mirembe F, Wabinga H. Patient delay in accessing breast Cancer Care in a sub Saharan African Country: Uganda. Br J Med Med Res. 2014;4(13):2599-610

37. Agodirin O, Olatoke S, Rahman G, et al. Delay between Breast Cancer Detection and Arrival at Specialist Clinic Preliminary Revelations of Multicentered Survey in Nigeria. Texila Int J Public Health. 2017;5(3). https://doi.org/10.21522/TIJPH.2013.05.04.Art053.

38. Agodirin O, Olatoke S, Rahman G, et al. Impact of Primary Care Delay on Progression of Breast Cancer in a Black African Population: A Multicentered Survey. J Cancer Epidemiol 2019; Article ID 2407138.

\section{Publisher's Note}

Springer Nature remains neutral with regard to jurisdictional claims in published maps and institutional affiliations.

Ready to submit your research? Choose BMC and benefit from:

- fast, convenient online submission

- thorough peer review by experienced researchers in your field

- rapid publication on acceptance

- support for research data, including large and complex data types

- gold Open Access which fosters wider collaboration and increased citations

- maximum visibility for your research: over $100 \mathrm{M}$ website views per year

At BMC, research is always in progress.

Learn more biomedcentral.com/submissions 